\title{
Inhibition Effects of Citrulline and Glutamine for Mild Steel Corrosion in Sulfuric Acid Environment: Thermodynamic and Kinetic Aspects
}

\author{
Arafat Toghan ${ }^{1,2}$, Ahmed Fawzy $y^{3,4, *}$, Nada Alqarni ${ }^{5}$,Adel Abdelkader ${ }^{2}$, Abbas I. Alakhras ${ }^{1}$ \\ ${ }^{1}$ Chemistry Department, College of Science, Imam Mohammad Ibn Saud Islamic University (IMSIU), \\ Riyadh 11623, Saudi Arabia \\ ${ }^{2}$ Chemistry Department, Faculty of Science, South Valley University, Qena 83523, Egypt \\ ${ }^{3}$ Chemistry Department, College of Applied Sciences, Umm Al-Qura University, Makkah 21955, \\ Saudi Arabia \\ ${ }^{4}$ Chemistry Department, Faculty of Science, Assiut University, Assiut 71516, Egypt \\ ${ }^{5}$ Chemistry Department, College of Science, University of Bisha, Bisha 61922, Saudi Arabia \\ *E-mail: afsaad13@yahoo.com
}

Received: 8 Augst 2021 / Accepted: 15 September 2021 / Published: 10 October 2021

\begin{abstract}
The inhibition of mild steel corrosion in sulfuric acid environment was evaluated by citrulline and glutamine at fixed temperatures. The tools used for this evaluation were potentiodynamic polarization (PDP), electrochemical impedance spectroscopy (EIS) and mass loss (ML) measurements. Also, the morphology of mild steel surfaces was examined prior to and after corrosion adding the tested inhibitors by scanning electron microscopy (SEM). The evaluated inhibition efficiencies (\% IEs) of the tested inhibitors increased with their concentrations but decreased with increasing sulfuric acid concentration. Results of PDP technique indicated that the examined compounds behaved as mixed inhibitors with cathodic majority. ML studies revealed that \% IEs reduced with increasing temperature. The investigational results acquired from all utilized techniques are agreeable with each others which disclosed that the \%IEs of citrulline were higher than glutamine under comparable conditions. The acquired great \% IEs of the tested inhibitors was understood on the basis of strong adsorption of amino acids on mild steel surface creating a defensive layer and this adsorption was noticed to accord with Langmuir isotherm. Thermodynamic and kinetic parameters were computed and discussed which confirm the physical adsorption mechanism of the examined inhibitors. The kinetics of the corrosion inhibition by such compounds revealed negative first order of corrosion inhibition process demonstrating the acquired great \% IEs of the investigated compounds.
\end{abstract}

Keywords: Mild steel, Amino acids, Corrosion inhibitors, Fuel cell, Thermodynamic \& kinetic aspects 
(C) 2021 The Authors. Published by ESG (www.electrochemsci.org). This article is an open access article distributed under the terms and conditions of the Creative Commons Attribution license (http://creativecommons.org/licenses/by/4.0/). 